\title{
El reclutamiento, los soldados y la experiencia del cuartel: servicio militar obligatorio en Perú y Colombia (1919-1933)
}

\author{
por \\ Carlos Camacho Arango ${ }^{1}$ \\ Centro de Estudios en Historia (CEHIS), Universidad Externado de Colombia
}

\begin{abstract}
Este artículo examina diferentes aspectos del servicio militar obligatorio en Perú y Colombia de 1919 a 1933: el proceso de reclutamiento, los orígenes de los soldados (sociales, «raciales» y geográficos) y su paso por los cuarteles de los ejércitos de ambos países. Sus fuentes principales son documentos de archivos militares de Estados Unidos y Francia, y escritos de oficiales y suboficiales peruanos y colombianos. El método es comparativo y muestra claramente rasgos comunes como la precariedad que afectaba a todos los aspectos del servicio.
\end{abstract}

Palabras Clave: Colombia; Conflicto de Leticia; Perú; reclutamiento; servicio militar obligatorio; soldados.

Cómo citar este artículo / Citation: Camacho Arango, Carlos, "El reclutamiento, los soldados y la experiencia del cuartel: servicio militar obligatorio en Perú y Colombia (19191933)", Revista de Indias, LXXVIII/272 (Madrid, 2018): 263-287. https://doi.org/10.3989/ revindias.2018.009

\section{INTRODUCCIÓN}

En el paso del siglo XIX al XX los ejércitos de América latina se transformaron uno tras otro, empezando por el de Chile, mediante un proceso doble: reforma militar (proceso nacional) y transferencias militares directas o indirectas de una potencia europea (proceso internacional). El objetivo principal de los Estados latinoamericanos era crear un nuevo tipo de oficial, más técnico y menos político que el existente, para comandar ejércitos verdadera-

\footnotetext{
1 camachoarango@gmail.com, ORCID iD: https://orcid.org/0000-0002-3332-5085.
} de uso y distribución Creative Commons Reconocimiento 4.0 Internacional (CC BY 4.0). 
mente nacionales y profesionales. Como es lógico, estos ejércitos necesitaban asegurar un flujo continuo de soldados. En los diferentes países se aprobaron entonces leyes sobre servicio militar obligatorio inspiradas en modelos transoceánicos. Si bien es cierto que la reforma y las transferencias han recibido algo de atención por parte de los historiadores, al servicio militar le han prestado muy poca y casi ninguna a los soldados, el componente humano más grande de cada ejército. El propósito de este artículo es empezar a llenar ese vacío historiográfico mediante la comparación de los casos de Perú y Colombia.

¿Por qué estos dos países? Porque las fuentes de transferencias militares que escogieron para poner en marchas sus reformas - Francia en Perú y Chile, Suiza y Alemania en Colombia - permiten contrastar dos procesos paralelos pero diferentes. Sus resultados, además, se pusieron a prueba de 1932 a 1933 en un conflicto de frontera, después de que un grupo de ciudadanos peruanos, civiles y militares, tomara por la fuerza el puerto colombiano de Leticia, en la orilla del Amazonas — en adelante Conflicto de LeticiaPor su carácter excepcional, este conato de guerra revela aspectos de la vida diaria de los soldados difíciles de encontrar en archivos y bibliotecas.

De hecho, la bibliografía sobre servicio militar obligatorio y soldados es reducida al extremo ${ }^{2}$ y el panorama en los archivos militares es aun peor: en Colombia, donde las dictaduras fueron la excepción, paradójicamente el acceso de los historiadores civiles al archivo militar es restringido; por el contrario, el Centro de Estudios Histórico-Militares del Perú mantiene abiertas sus puertas a los investigadores pero la falta de índices para los documentos del siglo XX hace casi imposible llevar a cabo una investigación exhaustiva ${ }^{3}$. Por fortuna, migajas de información puede recogerse con paciencia en archivos militares extranjeros, en particular en los de Francia y Estados Unidos. Estos países nombraron en varios momentos agregados militares.

Los norteamericanos habían trabajado en Lima en 1898 y luego entre 1907 y 1912, y en Bogotá, en 1908 y de nuevo entre 1915 y 1916. A partir de 1919 sus estadías fueron más prolongadas: en Colombia estuvieron de 1919 a 1920 y de 1927 a 1932, y en Perú, de 1919 a 19324. El aumento del interés de Washington por los ejércitos suramericanos se debió sin duda a la posición de poder en la que quedó al final de la Gran Guerra. El momento era propicio para empezar a atraer hacia su esfera militar a los vecinos del sur: los países

2 El estudio de referencia en Perú es el de Velásquez, 2013: 293-398. Aunque sólo se ocupa de los primeros años del siglo XX, no tiene equivalente en Colombia.

3 Estas afirmaciones se basan en la experiencia del autor.

4 National Archives Microfilm Publications, 1984: 7 y 10. 
europeos que habían sido por tradición las principales fuentes de transferencias militares, Alemania en particular, estaban debilitados. El primer paso para el acercamiento era conocer en profundidad las fortalezas y debilidades de estos ejércitos.

El retiro de los agregados de Lima y Bogotá a principios de los años 1930 no puede atribuirse a la crisis económica, de otra manera ¿cómo explicar que hayan permanecido hasta 1932? Es más probable que su partida haya obedecido al cambio en la política exterior de Washington hacia las demás naciones de América: en 1933 llegó a la presidencia Franklin Delano Roosevelt y se dieron los primeros pasos hacia la Good Neighbor Policy. En el nuevo contexto diplomático los agregados militares quizá sobraran.

París, por su parte, nombró agregados militares en Lima entre 1918 y 1919, y luego entre 1930 y 1933. Envió, además, una serie de misiones militares a Perú desde finales del siglo XIX hasta los años treinta - por ejemplo la sexta (1919-1922) y la séptima (1922-1924) - . La correspondencia e informes de instructores y agregados franceses revelan información valiosa sobre el ejército anfitrión.

Como puede verse, la presencia de oficiales extranjeros de distinto tipo fue mayor en los años 1919-1933 que en los precedentes o posteriores, lo que hace de este lapso un punto de observación privilegiado.

A los documentos de archivo se suman fuentes publicadas, sobre todo los informes anuales del Ministro de Guerra al Congreso de Colombia y algunos escritos de oficiales o suboficiales que tienen que ver, total o parcialmente, con el Conflicto de Leticia. El cese al fuego firmado en 1933 marca el límite de la investigación, cuyo marco temporal coincide entonces políticamente en Perú con los gobiernos consecutivos de Augusto Leguía (1919-1930 conocidos como Oncenio) y los de Luis Sánchez Cerro (1930-1931 y 1931-1933), y en Colombia, con las tres últimas presidencias (1918-1930) de lo que ha sido llamado Hegemonía Conservadora (1885-1930) y la primera del partido Liberal en el siglo XX (Enrique Olaya Herrera, 1930-1934).

El artículo está dividido en tres partes. La primera se ocupa del servicio militar obligatorio con énfasis en el proceso de reclutamiento y en el órgano de cada ejército que lo hacía posible. La segunda parte - y la primera también- estudia los orígenes de los soldados: sociales, «raciales» y geográficos. La última, que da nombre al conjunto ${ }^{5}$, pondera hasta qué punto el paso por el cuartel era una experiencia única en la vida de los jóvenes peruanos y colombianos que prestaban el servicio militar. 2000 .

5 Su título y varios interrogantes de este trabajo están inspirados en el libro de Roynette, 
Antes de entrar en materia conviene hacer dos advertencias. En primer lugar, no fue posible encontrar un solo testimonio de soldado - muy probablemente porque no existen-. Por lo tanto, la información siempre llega de manera indirecta: de civiles, oficiales y, en el mejor de los casos, suboficiales. En segundo lugar, los documentos disponibles no permiten, por el momento, hacer una comparación sistemática. Sin embargo, la comparación parcial no sólo deja ver mejor peculiaridades nacionales y rasgos comunes, sino que hace posible formular hipótesis de partida de investigaciones futuras.

\section{RECLUTAMIENTO}

Los soldados formaban el componente más numeroso de los ejércitos - con relación a oficiales y suboficiales - y la base de los mismos pues se encontraban debajo de las otras dos partes del cuerpo militar. Sin embargo, eran ellos quienes menos tiempo permanecían dentro debido a las leyes sobre servicio militar obligatorio aprobadas en ambos países a finales del siglo XIX $\mathrm{y}$ principios del siglo $\mathrm{XX}^{6}$. A pesar de las inmensas limitaciones que tuvo en estos años su puesta en marcha, estas leyes sí marcaron un quiebre. La novedad principal fue fijar límites temporales precisos: a la edad de los reclutas, al tiempo de servicio y a las épocas de reclutamiento. En el lapso estudiado el servicio se prestaba a una edad determinada, 21 años. Ya no se veían niños en los ejércitos, como había sido el caso en campañas del siglo XIX cuando escaseaban los hombres de tropa. Tampoco había soldados envejecidos: el tiempo bajo las banderas era el mismo para todos — dos años en Perú y uno en Colombia- ${ }^{7}$; podía prolongarse para resolver problemas en el centro del país o en sus confines, como ocurrió durante el Conflicto de Leticia, pero el soldado tenía, por lo general, una idea precisa del momento en que regresaría a la vida civil. Por último, el servicio empezaba en ciertas épocas precisas del año ${ }^{8}$. El reclutamiento ya no se hacía principalmente en los momentos en que se necesitaba tropas para la lucha.

${ }^{6}$ En Perú en 1898, Velásquez, 2013: 329. En Colombia en 1896, 1905 y 1909, Ministerio de Guerra, 1929: 16.

7 Plan de renseignements, 1931, Service Historique de la Défense, Département de l'Armée de Terre, Vincennes, Francia (SHD), série N (Troisième République, 1872-1940), sous-série 7N, 3411. Agregado militar en Bogotá al Director de Inteligencia Militar en Washington, 14 de agosto de 1929, National Archives and Records Administration, Washington, D. C. y College Park, Maryland, Estados Unidos (NARA), Record Group (RG) 165, 2010, 49-2.

8 En Perú los reclutas empezaron a entrar al mismo tiempo a lo cuarteles en 1906, Velásquez, 2013: 388. 
La idea de contingente se impuso: un grupo de jóvenes de la misma edad que entraba al ejército en un mes determinado — el mismo cada año- y regresaba a la vida civil después de haber prestado servicio un número fijo de meses. Se hablaba entonces del primer contingente de 1920, por ejemplo, o del segundo de 1932. El tamaño de estos contingentes lo determinaba el número máximo de soldados que podía tener cada ejército anualmente. Esta cifra era definida por el gobierno y se dividía entre el número de contingentes estipulados. Ni en los años veinte ni al principio de los treinta el número de soldados de cada ejército sobrepasó los 10.000. El de Colombia no alcanzaba siquiera los 8000 al final de $1929^{9}$; en marzo de 1930 un contingente terminó su tiempo de servicio pero no se llamó al de reemplazo, sin duda por la crisis económica: la tropa estipulada en 8.000 sólo alcanzaba la mitad en el momento en que el Partido Conservador entregó la presidencia al Liberal (agosto 1930 $)^{10}$.

La regularidad que el sistema de contingentes dio al servicio militar permitió crear, al menos sobre el papel, ejércitos de apoyo. En Perú la población militar estaba dividida en tres grupos: el ejército permanente compuesto por jóvenes entre los 21 y los 25 años; el ejército de reserva, entre los 26 y los 30 años; y el ejército territorial, entre los 30 y los $50^{11}$. En Colombia el ejército tenía tres «reservas»: la primera, compuesta por todos aquellos que hubieran prestado servicio y tuvieran entre 21 y 30 años; la segunda o guardia nacional, para los antiguos soldados entre 31 y 40 años; y la tercera, para los que no hubieran prestado el servicio, no estuvieran exentos y tuvieran entre 21 y 40 años ${ }^{12}$. Sin embargo, de acuerdo con el Agregado militar norteamericano, el gobierno colombiano no distinguía entre el número de hombres que podían portar armas (manpower) y el de hombres con un mínimo de entrenamiento militar (reserves): al final de los años veinte había unos 400.000 de la primera categoría pero sólo 70.000 de la segunda ${ }^{13}$.

Las normas que regían el servicio militar se llevaban a la práctica por medio de un grupo de oficiales encargado exclusivamente de recolectar infor-

9 Agregado militar en Bogotá al Director de Inteligencia Militar en Washington, 11 de diciembre de 1929, NARA, RG 165, 2010, 44-4. De acuerdo con Atehortúa, 2009: 124, el Ejército de Colombia llegó a 12.000 hombres en 1928.

10 Agregado militar en Bogotá al Director de Inteligencia Militar en Washington, 15 de septiembre de 1930, NARA, RG 165, 2010, 44-6.

11 Plan de renseignements, 1931, SHD, 7N, 3411.

12 Agregado militar en Bogotá al Director de Inteligencia Militar en Washington, 12 de mayo de 1919, NARA, RG 165, 2010, 4.

13 Agregado militar en Bogotá al Director de Inteligencia Militar en Washington, 13 de septiembre de 1929, NARA, RG 165, 34-3. 
mación sobre la población masculina y de reclutar a los jóvenes sobre el terreno. Estos oficiales conformaban uno de los servicios del ejército, el de reclutamiento, llamado también servicio territorial o regional. Mientras que en Perú su existencia fue continua, en Colombia fue esporádica: a pesar de que lo ordenaba una ley de 1909, este servicio sólo empezó a funcionar en 1920. Dos años después los 24 oficiales de reclutamiento fueron relevados de sus cargos y éstos, suprimidos. De acuerdo con el Ministro de Guerra de Colombia, estos oficiales ignoraban sus obligaciones, cometían atropellos y a veces violaban las disposiciones —el número de reclamos era muy alto — ${ }^{14}$. Durante la estadía de la Misión Militar Suiza (1924-1928) sus labores fueron confiadas al Estado Mayor General ${ }^{15}$.

Para efectos de reclutamiento el territorio de cada país estaba dividido en secciones. En Colombia eran llamadas «zonas» y coincidían con las divisiones del ejército, como deja verlo un mapa trazado en la segunda mitad de los años veinte. Cada zona de reclutamiento se extendía al menos por dos departamentos y una intendencia o comisaría - divisiones administrativas de menor rango- y estaba fraccionada en «cantones» que correspondían a los cuerpos de tropa. Los cantones, a su vez, estaban divididos en «distritos militares», cada uno de los cuales cubría dos municipios o más ${ }^{16}$. Los 24 oficiales que llegaron a conformar el servicio de reclutamiento sólo alcanzaban para ocupar los cargos en el nivel de cantones. Los distritos, por lo tanto, no estaban en manos de ningún oficial. El cubrimiento en Perú era mucho mayor. Allí la división militar del territorio para fines de reclutamiento coincidía mejor con la división política del país: dentro de cada provincia — subdivisión del departamento - había un oficial, con el título de jefe provincial. Debido al número de provincias era necesario contar en permanencia con 113 de estos jefes para asegurar el servicio territoria ${ }^{17}$. Los oficiales de ambos países debían trabajar en el nivel local. Por lo tanto los peruanos, al ser más numerosos y estar mejor distribuidos sobre el territorio, tenían en principio más probabilidades de llevar a cabo con éxito su labor.

El mecanismo de reclutamiento era similar. Los jóvenes debían inscribirse ante una junta compuesta, en Perú por las autoridades civiles municipales y el jefe militar provincial, y en Colombia, por las autoridades locales y un oficial. Civiles y militares dependían en ambos países de las autoridades re-

14 Ministerio de Guerra, 1920: 10; 1922: 20.

15 Ministerio de Guerra, 1927: 21.

16 Mapa de la actual división territorial militar, sin fecha, Biblioteca Luis Ángel Arango, Bogotá, Mapoteca, C 10006.

17 Étude, 8 de julio de 1924, SHD, 7N, 3412. 
ligiosas, ante la ausencia de sistemas de registro civil de la población: la iglesia católica tenía entonces la información más confiable sobre vivos y muertos pero no siempre estaba dispuesta a compartirla. Los curas, por lo tanto, eran determinantes en el momento de decidir quién prestaría el servicio militar y quién seguiría su vida civil sin interrupción. Los religiosos mismos estaban exentos por ley, al igual que muchos otros hombres por razones diversas, entre ellos todo aquel que pudiera estudiar ${ }^{18}$.

El poder inmenso de la iglesia unido a los medios reducidos del ejército - más reducidos en Colombia que en Perú - tenían consecuencias sobre el reclutamiento. En Perú, de acuerdo con el jefe de la sexta Misión Militar Francesa (1919-1922): «La inscripción no ha sido llevada con honradez, nunca se han hecho las transferencias de edades...». No se conocía la población militar del país pues «la depuración de los registros» se había hecho de manera superficial - en el mejor de los casos- ${ }^{19}$. En Colombia el comando de cada zona de reclutamiento, que no era otra cosa que el comando de cada división, debía llevar los registros tanto de quienes habían prestado el servicio como de los que no lo habían hecho. El Agregado norteamericano creía, con razón, que esos registros eran inexistentes o estaban desactualizados y ponía como ejemplo el fracaso de una movilización de prueba algunos años atrás ${ }^{20}$.

Otro problema común del reclutamiento en Perú y Colombia era la desproporción entre la población de cada país y el número ínfimo de soldados requeridos cada año. En Perú, por ejemplo, el contingente anual en 1920 era de 3.000 cupos mientras que el primero de enero de ese año había 45.000 hombres de 21 años ${ }^{21}$ : más del $90 \%$ de los jóvenes en edad de servir bajo las banderas continuaron tranquilamente su vida civil. El Agregado norteamericano en Bogotá, de su lado, hizo un cálculo interesante: teniendo en cuenta el tamaño del contingente en 1930, cada uno de los 731 municipios de Colombia sólo debía aportar, en teoría, una decena de hombres de 21 años $^{22}$. Se puede decir con certeza que, en los años previos al Conflicto de Leticia, prestar servicio militar en Perú y Colombia era una experiencia más bien rara entre los jóvenes.

18 Plan de renseignements, 1931, SHD, 7N, 3411. Agregado militar en Bogotá al Director de Inteligencia Militar en Washington, (probablemente abril) 1919, NARA, RG 165, 2010, 3. Velásquez, 2013: 348-349.

19 Memoria al coronel ministro de guerra, 1920, SHD, 7N, 3380.

20 Agregado militar en Bogotá al Director de Inteligencia Militar en Washington, 7 de mayo de 1928, NARA, RG 165, 2010, 27-4.

${ }_{21}$ Étude sur l'organisation militaire générale du Pérou, mayo 1920, SHD, 7N, 3380.

22 Agregado militar en Bogotá al Director de Inteligencia Militar en Washington, 22 de enero de 1930, NARA, RG 165, 2010, 19. 
¿Cómo se hacía entonces la selección? En principio era la suerte la que decidía. En ambos países los oficiales debían formar comisiones para los sorteos, en las que participaban las autoridades civiles. El oficial era el único militar y, por lo general, era forastero. Pese a lo que dijera la ley, eran las autoridades civiles y religiosas locales las que tenían el poder de decidir quién prestaba el servicio y quién no. Aquí contaban los lazos familiares, políticos, económicos y de otros tipos, que el oficial seguramente ignoraba. Y aun si los conocía no podía hacer mucho por evitar las trampas. Las exenciones no se limitaban al servicio mismo sino también al pago del impuesto para los que no prestaban ${ }^{23}$.

Al menos en Colombia el reclutamiento forzoso sobrevivió al siglo XIX, como lo denunció con vehemencia Tomás Rueda Vargas ${ }^{24}$, el más importante comentarista de asuntos militares en ese entonces: haber sido testigo de las consecuencias de esta práctica durante la guerra civil de 1885, cuando aún era un niño, definió, hasta cierto punto, su interés por mejorar las condiciones de la vida militar en Colombia. Así lo cuenta en un escrito autobiográfico:

Al principiar la guerra [finales de 1884, cuando tenía sólo 5 años] comenzó en los alrededores el bárbaro reclutamiento a la usanza de entonces: especie de cacería de hombres en que jugaba papel importante la delación. Recuerdo con horror la bajada de las Breñas de una partida de Chircaleños, mis amigos, en medio de dos filas de soldados. Al lado de afuera les acompañaban sus mujeres llorando estrepitosamente, y llevando alzados los muchachitos y los jotos de ropa; los ranchos quedaban abandonados. Fue tal mi terror que duré varios días sin salir, y ocultándome, al menor ruido, debajo de los muebles. Extrañada mi madre de mi actitud logró al fin que yo le confiara que obedecía al temor de que me reclutaran. Yo sabía que a los desertores los mataban a palo [...] También me ha acompañado el recuerdo de una anécdota que oí a mi abuelo, quien refería que en su condición de médico había tenido que asistir a un pobre labriego de algún pueblo de Cundinamarca que se había cortado la mano derecha con un hacha a fin de inhabilitarse para el servicio militar en aquellos tiempos odiosos ${ }^{25}$.

Todo lo anterior había contribuido en ambos países a darle una mala reputación no sólo al servicio militar entre la población civil, sino también al servicio de reclutamiento entre los oficiales. En Perú éste era el mejor medio que tenía el gobierno para mantener alejados de Lima a los oficiales subalternos cuya lealtad no estaba encima de toda sospecha — tal vez por eso había

23 Informe sobre el estado del ejército, 11 de noviembre de 1930, Archivo General de la Nación, Bogotá (AGN), Sección República (SR), Archivo privado Enrique Olaya Herrera $(\mathrm{EOH})$, caja 4, carpeta 17.

24 Rueda, 1969: 257-260.

25 Rueda, 1977: 297-298. 
tantos cupos- - La situación en Colombia la describió, con un nivel de detalle infrecuente, otro oficial subalterno, el capitán Muelle, en los últimos días del último gobierno Conservador: «Una absoluta y total incomprensión, una falta completa de honradez profesional y de patriotismo, han convertido nuestro servicio territorial militar, en un motivo de desprestigio y de vergüenza para la oficialidad». Sólo se destinaba allí a los oficiales sin influencia ni preparación o por motivos de edad. No había espacio para el oficial de reclutamiento en los alojamientos de los cuerpos de tropa ni tenía los materiales de trabajo necesarios. No se le daba dinero suficiente a él ni a su secretario para hacer «correrías» (cuatro al año) por muchos municipios. En cada uno tenía que hacer la inscripción el día del mercado, mientras los alcaldes estaban ocupados en otras faenas. Era imposible reunir las «juntas municipales de reemplazo» — compuestas por el oficial, el cura, el alcalde, el tesorero municipal y el secretario de la alcaldía - para solucionar los problemas que se presentaba. Los mismos oficiales contribuían a que los sorteos estuvieran viciados, metiendo boletas de dos tamaños en el sombrero, las grandes para los más sanos y las pequeñas para los menos: si los cuerpos de tropa rechazaban a los reclutas, el oficial era quien debía pagar su «pasaporte» de regreso al lugar de origen ${ }^{26}$. La estatura mínima debía ser, en teoría, 1.55 metros $\mathrm{y}$ el peso, 50 kilos $^{27}$ pero el promedio de los jóvenes que eran escogidos efectivamente para el servicio militar estaba en 1.65 y 61 respectivamente. De los 25.000 registrados al año, sólo un cuarto prestaba el servicio ${ }^{28}$.

El desprestigio del servicio de reclutamiento colombiano lo ilustra bien el caso del teniente Abraham Liévano, jefe de la sección de personal del departamento uno del Ministerio de Guerra en el primer año del gobierno Olaya Herrera (1930-1934). De acuerdo con un proyecto de decreto de marzo de 1931, este oficial debía pasar a retiro debido a su edad. El Ministro de Guerra Agustín Morales Olaya intercedió ante el Presidente de la República, su primo, por Liévano, a quien describió con estas palabras: «Mi antiguo amigo y a quien me ligan vínculos de una vieja amistad con sus familiares». El oficial, por su parte, pensaba que no había sido ascendido por razones políticas pero el Ministro mismo lo dudaba y creía más bien que había «dado motivos para

26 Justicia (situación técnica y moral en que se hallaba el ejército, el día de la transmisión de mando siete de agosto de 1930), 25 de julio de 1930, AGN, SR, EOH, caja 4, carpeta 17 .

27 Agregado militar en Bogotá al Director de Inteligencia Militar en Washington, 21 de abril de 1928, NARA, RG 165, 2010, 36-1.

28 Agregado militar en Bogotá al Director de Inteligencia Militar en Washington, 17 de abril de 1928, NARA, RG 165, 2010, 37-1. 
colocarse en un plano de inferiores prendas a muchos otros de sus colegas». Morales Olaya le envió a Olaya Herrera la hoja de vida de Liévano y le pidió consejo sobre lo que debía hacer: si lo dejaba en filas sentaría un mal precedente pues venía retirando del ejército en «forma irrestricta» a los oficiales que llegaban a la edad de retiro ${ }^{29}$. Pese a que la respuesta del Presidente no dejó rastro en los archivos, sí se conoce la solución del problema: el Ministro sugirió nombrarlo en el servicio de reclutamiento como comandante del distrito territorial número cuatro — «Así tendría dos años más para ascender»—. Liévano quedó complacido y esperaba ser nombrado en comisión en la Escuela de Aviación por resolución del Ministerio ${ }^{30}$.

Como se dijo, no sólo el servicio de reclutamiento tenía mala reputación en Colombia: el servicio militar mismo estaba desprestigiado entre el público. Algunas familias veían los cuarteles como «casas de corrección» y los usaban como castigo para hijos rebeldes ${ }^{31}$ pero la mayoría no quería que sus hijos sirvieran en el ejército y buscaba la forma, legal o ilegal, de evitarlo. La manera más sencilla era esconderse: en época de reclutamiento muchos jóvenes se iban de sus casas. Cuando se puso en marcha efectivamente el servicio militar obligatorio (1912) la ley permitía la exención por dinero. Dos años más tarde fue abolida y se instituyó en su lugar la exención «por reemplazo»: una persona podía prestar el servicio militar por otra. Tomás Rueda Vargas la consideraba, con toda razón, una «fuente de iniquidades sin término» y hablaba de la «eterna carne de cañón»: la de los pobres ${ }^{32}$. En 1919 había dos sustitutos por cada joven seleccionado pero la costumbre de pagar para no prestar persistía en la ilegalidad: el Agregado de Estados Unidos sabía que algunos oficiales estaban dispuestos a recibir dinero de gandules que querían evadir el servicio ${ }^{33}$.

Diez años después se creó un impuesto «de defensa nacional» que funcionaba así: al llegar a la edad de conscripción todos los ciudadanos debían presentarse en los meses de noviembre y diciembre. Según sus capacidades económicas se clasificaban en siete clases, de las cuales la primera era la más alta. Para cada clase se fijaban el impuesto y la «prima de exención»: el primero para los que no salían sorteados y la segunda para los que sí, pero no

29 Teniente Liévano a Morales Olaya, 13 de febrero de 1931 y Morales Olaya a Olaya Herrera, 20 de febrero de 1931, AGN, SR, EOH, caja 4, carpeta 17.

30 Morales Olaya a Olaya Herrera, 5 de marzo de 1931 y 13 de marzo de 1931, AGN, SR, EOH, caja 4, carpeta 17.

31 Ministerio de Guerra, 1922: 21.

32 Rueda, 1969: 67 y 109-110.

33 Agregado militar en Bogotá al Director de Inteligencia Militar en Washington (probablemente abril), 1919, NARA, RG 165, 2010, 3. 
querían prestar el servicio. Ambos se pagaban una sola vez. La clase siete no pagaba nunca por ser «pobres de solemnidad». Las cuotas eran las siguientes (impuesto y prima): primera clase 100 y 300, segunda 70 y 250 , tercera 50 y 200 , cuarta 30 y 150 , quinta 15 y 100 , y sexta 5 y 50 . Como puede verse la «prima» para la primera clase era sólo tres veces el monto del impuesto, mientras que para la sexta, en el borde de la pobreza «de solemnidad», era diez veces. En otras palabras, el servicio militar sólo era obligatorio para los pobres que salían «favorecidos». Al empezar el gobierno de Olaya Herrera el Ministro de Guerra veía en las leyes vigentes sobre servicio militar «un acto de justicia» ya que distribuían «entre todos los colombianos, sin distinción de clases, la pesada obligación de prepararse para la defensa nacional» ${ }^{34}$. El peso de la defensa se repartía, no hay duda, pero hablar de justicia era abusar. Más verosímil era la metáfora usada por uno de sus antecesores en el cargo, quien habló del reclutamiento como la «contribución de sangre» que correspondía a los ciudadanos 35 - pobres-.

Dos afiches sobre el empréstito lanzado por el gobierno colombiano en septiembre de 1932 para hacer frente a la guerra en germen con Perú ayudan a entender la manera en que los colombianos veían el servicio militar obligatorio. El primero se imprimió y distribuyó por todo el departamento de Antioquia, el menos pobre de Colombia. En él se podía leer:

Una victoria sin sacrificios.

La primera victoria, probablemente la victoria definitiva de nuestra causa, será la completa suscripción del Empréstito Patriótico. ¿Quiere usted participar en esa victoria del honor y de la soberanía nacionales sin sacrificio de su tranquilidad y de la sangre de sus hijos? Compre bonos de la defensa nacional ${ }^{36}$.

El otro afiche fue diseñado por un artista italiano radicado en Bogotá: Rinaldo Scandroglio. Está dividido en cuatro franjas. En la inferior puede leerse: «Empréstito de la defensa nacional». En la siguiente un grupo de personas, iluminado, con vestidos suntuosos y bolsas con la palabra «oro» y el signo $\$$ en sus manos, se dirige hacia la izquierda. En la siguiente desfilan oscuros soldados en sentido contrario. Una frase escrita en la franja superior da sentido al conjunto: «Cada uno cumpla con su deber» ${ }^{37}$. El lema confirma la repartición de las cargas de la defensa nacional entre los colombianos, tal

\footnotetext{
34 Ministerio de Guerra, 1931: 29-30 y 60.

35 Ministerio de Guerra, 1927: 20.

36 Donadio, 1995: 195.

37 Afiche "Cada uno cumpla con su deber", Museo Militar de Bogotá.
} 
como lo proclamaba el Ministro de Guerra, pero es dudoso que la gente viera en este estado de cosas un acto de justicia.

\section{ORÍGENES}

Todo indica que no hubo en Perú exención por dinero. Sin embargo, el servicio militar no era obligatorio para todo el mundo. Otras razones contribuían a la iniquidad y le daban a los contingentes su aspecto peculiar. Una de ellas era la predilección de reclutar en la Sierra (Andes). El caso del primer regimiento de artillería, destacado en la ciudad de Trujillo en 1931, sirve de ejemplo. Cuando el suboficial Luis Chanduví llegó allí «toda la tropa estaba compuesta por conscriptos oriundos del departamento de La Libertad, el 60\% era de la Sierra y los restantes gente criolla procedente del valle de Chicama ${ }^{38}$. El porcentaje mayoritario es interesante si se tiene en cuenta que Trujillo está situada en la Costa. Como queda dicho, el servicio de reclutamiento peruano cubría de manera homogénea el territorio. ¿Cómo explicar entonces esta preferencia de una región sobre las otras? Tal vez por la fama que tenían los habitantes de la Sierra, «indios» en su gran mayoría. Para los jefes de las Misiones Militares Francesas el indien era el soldado ideal: pese a su apariencia pesada y a su semblante triste, a su naturaleza robusta y a su inteligencia lenta, era fácil de instruir, además de ser «de carácter dócil, por tanto disciplinado, de una sobriedad ejemplar, muy resistente a la fatiga ${ }^{39}$. El Agregado norteamericano en Lima completaba el retrato hablado del indian: desarrollo mental muy bajo, por lo general analfabeto, pero muy resistente, con el sentido de la vista muy desarrollado y supremamente valiente: «La historia ha mostrado que prefiere morir antes que entregar la posición que se le ha ordenado ocupar» ${ }^{40}$. En cualquier caso, el hecho de que el $40 \%$ de la tropa del primer regimiento de artillería no viniera de la Sierra ya podía considerarse un avance frente a «las inveteradas prácticas de reclutamiento por

38 Chanduví, 1988: 19.

39 "De caractère docile, par suite discipliné, d'une sobriété exemplaire, très résistant à la fatigue”, Grl Vassal, Memoria al coronel ministro de guerra, 1921, SHD, 7N, 3380, f. 1. Grl Pellegrin, Etude, 8 de Julio de 1924, SHD, 7N, 3412.

40 "History has shown that he will die rather than give up a position he is ordered to hold”, Agregado militar en Lima al Director de Inteligencia Militar en Washington, 17 de mayo de 1926, NARA, RG 165, 2033, 93-3. Las mismas opiniones —y también las contrarias - se oyeron en Lima a finales del siglo XIX en el debate público sobre la pertinencia de militarizar la sociedad peruana, Velásquez, 2013: 322-326. 
las cuales la casi totalidad del Ejército era extraída de los pueblos y caseríos serranos» ${ }^{41}$.

En Colombia los estereotipos sobre las regiones también parecían determinar dónde se reclutaba con mayor empeño. El Agregado norteamericano los transcribía: los soldados de la costa Caribe eran perezosos y no tenían apariencia militar, mientras que los del centro del país eran más altos, más fuertes y tenían mejor aspecto. Según este oficial diplomático, los últimos eran de un tipo superior debido a los esfuerzos de las razas que vivieron y penetraron en los valles y altiplanos andinos, y también al hecho de haber tenido un poco más de educación que los costeños. Si los oficiales evitaban ser destacados en algunas guarniciones del Caribe, esto no se debía al clima sino a las dificultades de lidiar con los soldados que encontraban allít2.

La oposición costa-centro en Colombia se entiende mejor si se tiene en cuenta también los orígenes de la tropa en el nivel de los departamentos y no sólo de las regiones. Según el sargento Jorge Tobón los primeros batallones de Antioquia y Santander que llegaron a la frontera con Perú después de la toma de Leticia estaban compuestos por soldados malos e indisciplinados, que contrastaban con los soldados de Nariño, «sufridos, disciplinados y sumisos». Tobón atribuía la diferencia a las razas que poblaban cada departamento ${ }^{43}$ : en Antioquia y Santander había predominio «blanco» en el mestizaje mientras que en Nariño el elemento indígena era más evidente. De acuerdo con Tomás Rueda Vargas el reclutamiento estaba «cebado» en Boyacá y «ciertas regiones de Cundinamarca» ${ }^{44}$ - parecidos étnicamente a Nariño-. Esto no se explica por la importancia del elemento indígena en la población de estos departamentos sino por el hecho simple de que el altiplano cundi-boyacense concentraba la mayor cantidad de unidades del ejército en todo el país. En este caso importante una larga tradición de reclutamiento habría creado una imagen favorable de los soldados. Lo mismo podría decirse de la Sierra peruana: la leva precedía a la fama, no la fama a la leva.

El hecho de que en ambos países fuera más fácil reclutar jóvenes en los centros urbanos que en el campo ${ }^{45}$ - debido al cubrimiento geográfico de los servicios de reclutamiento - sugiere que la mayoría de los soldados provenía

\footnotetext{
41 Velásquez, 2013: 341-342.

42 Agregado militar en Bogotá al Director de Inteligencia Militar en Washington, 6 de enero de 1930, NARA, RG 165, 2010, 37-2.

43 Tobón: 64-65.

44 Rueda, 1969: 191.

45 Agregado militar en Lima al Director de Inteligencia Militar en Washington, 8 de febrero de 1924, NARA, RG 165, 2033, 101.
} 
de ciudades o de sectores rurales circundantes. En estos espacios era más fácil encontrar escuelas primarias que en el campo profundo. La distribución geográfica del reclutamiento tendría como consecuencia un nivel educativo mínimo entre la tropa, al menos en Colombia, en contra de la imagen difundida del soldado analfabeta ${ }^{46}$. La única información de tasas de alfabetización se encontró en la investigación de Adolfo Atehortúa sobre reforma militar y misiones extranjeras en Colombia. Se trata de una muestra al azar de hojas de vida de 82 suboficiales activos entre 1925 y 1932. Todos habían entrado al ejército como soldados y es dudoso que hubieran estudiado después de su ingreso. Los datos sirven, en principio, para hacerse una idea de la educación de la tropa. Sin embargo, saber leer y escribir era requisito para convertirse en suboficial. Por lo tanto las conclusiones que se sacan para estos suboficiales no se extienden automáticamente hasta los soldados.

Sobre el total de 82 suboficiales, ocho eran analfabetas (9.7\%), 30 habían empezado la educación primaria y habían abandonado la escuela sin terminarla $(36.5 \%)$ - probablemente después de haber aprendido a leer y a escribir-, 18 habían terminado $(21.9 \%)$ y otros tantos habían asistido hasta tres años a la escuela secundaria $(21.9 \%)$ - sobre los ocho restantes no hay información- La conclusión de Atehortúa es la siguiente: «Al final de la hegemonía conservadora [1930] el conscripto en los cuarteles colombianos, como incluso gruesa parte de los suboficiales, era en considerable porcentaje analfabeta o había recibido apenas las primeras letras en la escuela elemental» ${ }^{47}$. 9.7 (analfabetas) no es un porcentaje «considerable»; 36.5 (primaria sin terminar) sí, pero no es adecuado sumar estos porcentajes ni juntar las dos categorías ya que desaparece la frontera entre los hombres que, con toda probabilidad, sabían leer y escribir, y los que no.

Los datos biográficos del soldado Cándido Leguízamo, disponibles gracias a la notoriedad que le dio su muerte ${ }^{48}$, hacen pensar que, al menos en Colombia, los soldados alfabetizados no eran tan escasos. Leguízamo había nacido el tres de octubre de 1911 «en la fracción rural de Ceibas Adentro del municipio de Neiva», es decir en un lugar situado a medio camino entre la ciudad y el campo. Pese a que su modo de vida era campesino - «venía a Neiva semanalmente arreando las bestias cargadas de víveres y café»—- había apren-

46 En Perú la mayoría de los soldados eran alfabetizados en los cuarteles al empezar el siglo XX, Velásquez, 2013: 392-396.

47 Atehortúa, 2009: 158-159.

48 Leguízamo resultó herido en una escaramuza con tropas peruanas en la orilla derecha del río Putumayo; trasladado a Bogotá, murió y fue sepultado como héroe nacional. 
dido a leer y escribir, como deja verlo su diálogo con un oficial, transcrito en detalle y de inmediato por el auditor de guerra - y poeta - Carlos López:

- A yo sólo una cosa me provoca, mi coronel.

- A ver, chatico, dila; no sabes con qué gusto..

- Mi coronel, yo quisiera que me consiguiera recao p'a escribirle a mi teniente.

Ayerve y decirle que mande por yo apenas pueda ${ }^{49}$.

Su manera de hablar era rústica pero el «recao» que pide es recado de escribir. ¿Era excepcional el caso de este soldado? Leguízamo no se incorporó al ejército en medio de la fiebre patriótica que desató la toma de Leticia, cuando se ofrecieron a prestar servicio militar personas que en otras condiciones no lo habrían hecho. De acuerdo con su compañero de contingente, Cenón Artunduaga, ambos jóvenes empezaron a cumplir su obligación en septiembre de $1930^{50}$, en las mismas condiciones en que miles de colombianos lo habían hecho antes.

Dos documentos de naturaleza diferente sobre el Conflicto de Leticia confirman la impresión de que los soldados colombianos analfabetas eran la excepción más que la regla. El piloto alemán y oficial honorario del Ejército de Colombia, Herbert Boy, escribió en sus memorias: «Yo les llevaba, junto con vituallas y medicamentos, algún periódico o una carta, un papel escrito con lápiz y 'a ruego' en la telegrafía del pueblo. En la guarnición se lo pasaban de mano en mano, pues aunque no fuera dirigido sino a uno solo de los soldados, parecía llevarles a todos el aroma y sabor del terruño» ${ }^{51}$-el papel escrito «a ruego» hace pensar que los analfabetas eran los padres de los soldados y no los soldados-. Y en una película filmada en el frente se les ve recibiendo correspondencia en el frente y leyéndola ${ }^{52}$.

Dos precisiones se hace necesarias en este punto. En primer lugar, aun si todos los soldados colombianos, y peruanos, sabían leer y escribir, eso no era indicador del nivel de alfabetización de la población: los contingentes eran demasiado reducidos para ser representativos de la juventud de cada país. En segundo lugar, saber escribir no garantizaba escribir regularmente. De hecho no se encontró ningún diario ni autobiografía que de cuenta de la experiencia del cuartel. Para hacerse una idea de ella es necesario echar mano de otras

49 López, 1951: 44.

50 Díaz, 1972: 43.

51 Boy, 1955: 175 y 181 .

52 Guerra con el Perú, Fundación Patrimonio Fílmico Colombiano (FPFC), Archivo histórico cinematográfico de los hermanos Acevedo (AHCHA), código DVD 6018-6019, hora 1 , minuto 32, segundo 58, cuadro 18 . 
fuentes: la vida del soldado siempre es vista a través de los ojos de oficiales, suboficiales o civiles.

\section{LA EXPERIENCIA DEL CUARTEL}

El rasgo más notorio del servicio militar era la pobreza en que se prestaba. En 1920 los cuarteles de propiedad del Estado eran muy pocos. Esto no habría sido tan traumático si los edificios alquilados hubieran estado diseñados para las necesidades militares. En Perú muchos regimientos, sobre todo en provincia, vivían en casa viejas, mal distribuidas e insalubres, por las que se pagaban arrendamientos elevados. Sólo en Lima había instalaciones en número más o menos suficiente, en antiguos conventos, hospitales, lazaretos... Las consecuencias eran graves: Bonaventure Vassal, jefe de la sexta Misión Militar Francesa en Perú (1919-1922) hablaba de la «mortalidad ocasionada por la falta de comodidad e higiene actuales» ${ }^{53}$. En Colombia el ejército no tenía un solo cuartel propio: todos eran alquilados a particulares. En ambos países los primeros intentos de resolver este problema fueron iniciativas individuales: en Cali, Colombia, el «general don» Lucio Velasco, viejo líder político-militar de guerra civil, empezaba a construir con dineros privados el primer cuartel del ejército en 1920 - lo que lo hacía merecedor de las loas del Ministro de Guerra—54; y en Sicuani, Perú, pocos años después el teniente coronel Ernesto Montagne construía también un cuartel adecuado para sus hombres, financiado por la comunidad, sus oficiales y otros medios, sin la ayuda de Lima $^{55}$.

El Estado colombiano empezó a comprar, más que a construir, edificios para el ejército: en 1922, siete cuerpos de tropa de los 24 existentes ya tenían cuarteles propios. El impulso no duró mucho: hubo años en que no se destinó siquiera partidas para este rubro en el presupuesto de Guerra -1927, por ejemplo- Cuatro años más tarde, en plena época de crisis, el Ministro presentaba al Congreso el «cuartel moderno» ideal pero los disponibles databan de la era antigua ${ }^{56}$. De acuerdo con un capitán, los alojamientos no tenían ventilación suficiente: «El oficial de servicio no puede visitar estos dormitorios durante la noche, porque al entrar, la atmósfera que allí se respira es

53 Grl Vassal, Rapport, 26 de enero de 1920, SHD, 7N, 3380, f. 4. Grl Vassal, Memoria al coronel ministro de guerra, mayo 1920, SHD, 7N, 3380 .

54 Ministerio de Guerra, 1920: 47 y 49.

55 Montagne, 1962: 57-70.

56 Ministerio de Guerra, 1920: 47 y 49; 1922: 29; 1927: 34; 1931: entre 40 y 41. 
nauseabunda» ${ }^{57}$. El estado de las instalaciones peruanas al empezar los años treinta lo reflejaba bien el cuartel O'Donovan, del primer regimiento de artillería, destacado en Trujillo, cuya toma por militantes y simpatizantes civiles apristas en julio de 1932 marcó un hito en la historia de Perú. Antes de servir al ejército había sido una leprosería. De acuerdo con el sargento Luis Chanduví: «De cuartel solamente tenía el nombre, estaba constituido por varios pabellones de madera [...] no tenía muros en el frente, a los lados los tenía de adobe, con la altura que se estila para una casa ${ }^{58}$. Los edificios no tenían campos de entrenamiento anexos: se utilizaba entonces el lote desocupado más cercano. En Perú la excepción era Chorrillos pero su campo sólo servía para hacer ejercicios de orden cerrado ${ }^{59}$. El orden cerrado también era preferido en Colombia gracias, en parte, a que muchos cuarteles funcionaban en claustros como los antiguos conventos de San Agustín y de San Diego en Bogotá, que sirvieron de sede a la Escuela militar. Los polígonos, por su parte, eran arrendados por alto precio y sólo en algunas épocas del año ${ }^{60}$.

En Perú, el general Vassal comparaba el estado en que había encontrado los depósitos de la intendencia en 1919 con el que tenían en tiempos de las Misiones Francesas anteriores a 1914: el stock había desaparecido pese a que las partidas correspondientes siempre habían estado en los presupuestos. El Estado no tenía los medios de producción, por lo cual debía pagar precios muy altos a terceros. Como resultado ninguna división tenía existencias suficientes de uniformes o equipo ${ }^{61}$. En Colombia, los depósitos y reservas de armamento, municiones y material de guerra eran insuficientes, como lo eran los talleres para la confección de vestuario y equipo. Según el Ministro de Guerra en 1920, las movilizaciones que se habían hecho por orden público y como ejercicio habían mostrado «la completa deficiencia de nuestros servicios en lo que se relaciona con el material» ${ }^{62}$.

El estado de la intendencia en Colombia ponía de manifiesto algunos problemas. En primer lugar, las partidas votadas no eran definidas en función de estudios que tuvieran en cuenta las necesidades reales del ejército sino con

${ }^{57}$ Cpt Muelle, Justicia (situación técnica y moral en que se hallaba el ejército, el día de la transmisión de mando siete de agosto de 1930), 25 de julio de 1930, AGN, SR, EOH, caja 4, carpeta 17.

58 Chanduví, 1988: 18.

59 Agregado militar en Lima al Director de Inteligencia Militar en Washington, 8 de julio de 1927, NARA, RG 165, 2033, 130.

60 Ministerio de Guerra, 1920: 49.

61 Grl Vassal, Rapport, 26 de enero de 1920 y Grl Vassal, Étude sur l'organisation militaire générale du Pérou, septiembre 1920, SHD, 7N, 3380.

62 Ministerio de Guerra, 1920: 43. 
base en la costumbre $-\mathrm{y}$ eran reducidas sin piedad en caso de crisis-. El segundo problema era la dependencia casi absoluta de fábricas extranjeras, que, si bien era explicable en lo que tenía que ver con armamento, era más difícil de entender cuando se trataba de prendas y accesorios. De acuerdo con el Ministro de Guerra los uniformes se compraban en otros países porque los nacionales salían defectuosos y eran muy costosos. Por último, la centralización en la capital era excesiva: el material de guerra estaba mal distribuido en las guarniciones de provincia. Para solucionar los dos últimos problemas se hicieron proyectos de descentralización, como la creación de talleres en las sedes de los comandos divisionarios: todo el decenio del veinte se habló de confeccionar el vestuario con elementos nacionales ${ }^{63}$, en vano.

Las consecuencias eran evidentes, en el sentido literal de la palabra. En 1922 el equipo y el correaje de los soldados colombianos completaban más de ocho años sin renovarse ${ }^{64}$. En ese momento el calzado predilecto era la alpargata. El Ministro de Guerra propuso suprimirla en 1925 «al menos en la época de paz» ${ }^{65}$. Cuatro años después el Agregado de Estados Unidos en Bogotá informaba a Washington que los soldados colombianos sólo usaban zapatos en los desfiles y sus uniformes eran andrajosos: el resultado era una apariencia muy poco militar ${ }^{66}$. Su colega en Lima no transmitía noticias mejores: la apariencia del Ejército Peruano era «excepcionalmente mala». En una revista que tuvo lugar en 1931 la única unidad que tenía aspecto militar era la Escuela de Chorrillos ${ }^{67}$.

Sin embargo, estas impresiones parecidas no deben ocultar las diferencias que había en el material almacenado en los depósitos de los dos países al empezar el Conflicto de Leticia: los poquísimos soldados colombianos que se encontraban en la frontera andaban descalzos, vestían prendas civiles o una combinación civil-militar y debían aportar ellos mismos sus útiles de alojamiento, aseo personal y menaje. Los primeros refuerzos llegaron también descalzos, sin ropa de cambio ni toldillos ni equipos completos ${ }^{68}$ : la idea misma de uniforme se esfumaba en la realidad. Se puede hablar entonces de

63 Ministerio de Guerra, 1920: 37 y 43; 1922: 28; 1924: 73; 1927: 32-33; 1931: 39.

${ }^{64}$ Ministerio de Guerra, 1922: 28.

65 Ministerio de Guerra, 1925: 32.

${ }^{66}$ Agregado militar en Bogotá al Director de Inteligencia Militar en Washington, 14 de septiembre de 1929, NARA, RG 165, 2010, 34-4.

67 Agregado militar en Lima al Director de Inteligencia Militar en Washington, 11 de junio de 1931, NARA, RG 165, 2033, 152-1.

68 Capitán Bejarano al coronel Rico, 8 de septiembre de 1932 y Coronel Rico al Ministro de Guerra, 21 de octubre de 1932, AGN, SR, documentación histórica conflicto colombo-peruano (CCP), caja 9. 
una «desuniformización» debida a la precariedad. En el otro lado de la frontera, por el contrario, había vestuario y equipo para más de 3.000 hombres, lo que hizo innecesario el envío de «fornituras» desde Lima al empezar el Conflicto de Leticia ${ }^{69}$. Seguramente los oficiales y suboficiales enviados desde la capital llegaban con sus elementos pero no debe olvidarse que los soldados fueron reclutados sin excepción en la Amazonia peruana y, por lo tanto, llegaban a Iquitos en prendas civiles y sin equipo de campaña. El Ejército de Colombia, por su parte, tuvo que comprar «gran parte» del vestuario en el exterior y todo el calzado en Chile: el par de botas, llevado hasta Buenaventura, en la costa del Pacífico, valía 1,15 pesos, mientras que en Colombia las ofertas no bajaron de $2,50^{70}$.

La instrucción civil y militar, y dentro de ésta, la instrucción teórica y práctica, se resentía por la escasez de recursos en ambos países: papel, lápices, pizarras, mapas, textos, armas, munición, terrenos... En Perú la afectaba además el movimiento constante de los oficiales de una guarnición a otra ${ }^{71} \mathrm{y}$ en Colombia, el movimiento de la tropa para prestar servicios de policía: las revistas de instrucción y los informes enviados por los comandos de división mostraban deficiencias serias ${ }^{72}$. Según el Agregado norteamericano en Bogotá, la instrucción de las tropas colombianas era «elemental al extremo» ${ }^{73}$. En Perú, al parecer no era tan mala: en un informe extremadamente crítico redactado poco antes de dejar el país, François Pellegrin, comandante de la séptima Misión Francesa (1922-1924), afirmaba que la instrucción de la tropa era «bastante buena» ${ }^{74}$. Dos años después el Agregado de Estados Unidos en Lima calificaba esta instrucción de «pasable», comparada con «excelente» en las nuevas unidades de policía y «descuidada» en la gendarmería, con excepción de Lima $^{75}$.

Otra característica del paso por el ejército era la rutina. Si las tropas no estaban ocupadas en labores de policía, llenaban las horas con actividades

69 Teniente coronel Calderón al coronel Beingolea, 17 de septiembre de 1932, Centro de Estudios Histórico-Militares del Perú, Lima (CEHMP), Diario de marchas y operaciones de la quinta división del Ejército Peruano (DMOQD).

70 Uribe, 1933: 31.

71 Grl Vassal, Memoria al coronel ministro de guerra, 1921, SHD, 7N, 3380. Ministerio de Guerra, 1922: 14.

72 Ministerio de Guerra, 1920: 12 y 26; 1924: 78-79.

73 Agregado militar en Bogotá al Director de Inteligencia Militar en Washington, 14 de abril de 1928, NARA, RG 165, 2010, 35-1.

74 "Plutôt bonne", Grl Pellegrin, Étude, 8 de julio de 1924, SHD, 7N, 3412.

75 "Fair", "excellent", "neglected", Agregado militar en Lima al Director de Inteligencia Militar en Washington, 30 de abril de 1926, NARA, RG 165, 2033, 117. 
monótonas como la guardia, los ejercicios de orden cerrado y la memorización de poemas o canciones patrióticas. El sargento Jorge Tobón, por ejemplo, recuerda en sus memorias las primeras líneas del himno de los reclutas: «Soldado de Colombia me llamo con orgullo, mis caras ilusiones las tengo en el cuartel $\gg^{76}$. En estas condiciones era difícil distinguir un día de otro y fácil terminar haciendo actividades inútiles y aun contraproducentes, como pudo constatarlo Oscar Sevilla, teniente coronel del Ejército Peruano, antes de atacar la posición colombiana de Calderón durante el Conflicto de Leticia.

Desde la orilla peruana del río Putumayo observó la vida diaria de esta guarnición. A su superior informó que había orden y limpieza, las tropas estaban bien vestidas y calzadas, y dedujo que tenían buen espíritu pues las oyó corear canciones patrióticas y hacer ejercicios y «academias» (instrucción) - se trataba de refuerzos recién llegados al frente con recursos que no tuvieron las primeras tropas-. Agregó que los militares colombianos eran «muy amigos a [sic] las evoluciones en orden cerrado» pero lo más interesante de su reporte está en el párrafo siguiente: «Por declaraciones de un preso colombiano tomado en el reconocimiento a Yabuyanos, he sabido que los colombianos habían dicho que la sorpresa de Calderón tuvo lugar cuando la tropa se hallaba pasando 'revista de uñas', queriendo denotar con esto que el capitán de la compañía poseía aquel espíritu detallista de nuestros antiguos oficiales de infantería, ya desaparecidos ${ }^{77}$. El coronel Sevilla retoma aquí un rumor que aparece también en el lado colombiano en los diarios de guerra del capitán Hernando Mora y del auditor de guerra Carlos López: la emboscada peruana a Calderón ocurrió cuando un oficial colombiano verificaba, en una situación de guerra inminente en plena Amazonia, que las uñas de sus subordinados estuvieran limpias ${ }^{78}$. Tal vez se trata de una exageración pero ningún documento consultado intenta refutar esta noticia, lo que hace pensar que, si no era verdadera, al menos era verosímil.

A todo lo anterior hay que agregar que el servicio militar obligaba a dejar la familia y el estilo de vida habitual para entrar a formar parte, en el nivel más bajo, de un grupo humano en el que las relaciones jerárquicas estaban mucho más formalizadas que en la vida civil: pobreza, rutina, ruptura con todo lo que era familiar... en estas condiciones es fácil pensar que los soldados quisieran escapar de los cuarteles. Sin embargo, la deserción no aparece entre los problemas militares graves de Perú y Colombia. ¿Por qué permanecían entonces los jóvenes en el ejército? Evidentemente pesaba sobre ellos la

\footnotetext{
76 Tobón: 83.

77 Teniente coronel Sevilla al coronel Ramos, 3 de mayo de 1933, CEHMP, DMOQD.

78 Mora, 1994: 297. López, 1951: 165.
} 
amenaza del castigo pero, al menos en Colombia, el Estado no tenía los medios para punir a remisos y desertores. Al hablar sobre «la organización judicial militar, los procedimientos y los delitos militares y sus penas», el Ministro de Guerra afirmaba: «Aun cuando el decreto número 1144 de 1911, fija penas (en prisiones militares) a las cuales pueden ser enviados los delincuentes por los tribunales militares respectivos, no existen ni prisiones militares ni tribunales especiales; pues en la Legislación Penal Militar no se mencionan tales tribunales y por consiguiente su creación y funcionamiento serían ilegales» ${ }^{79}$.

Otros factores explican la resignación de los soldados. En lo que tiene que ver con la precariedad material, las condiciones de la vida militar no eran necesariamente más penosas que las de la vida civil precedente: la mayor parte de los soldados, quizá todos, venía de hogares donde la pobreza era la realidad cotidiana. Las declaraciones que hizo a la prensa en 1930 un sacerdote de familia adinerada, Camilo Villegas Ángel, sobre la mayoría de sus colegas religiosos resultan esclarecedoras: «A los seminarios van en alto porcentaje los hijos de campesinos, acostumbrados a comer arepa de mangarracho, a dormir sobre tendidos de caña brava, a vestir coleta y driles ásperos» ${ }^{80}$. Estos novicios eran tal vez los protegidos del cura del pueblo, quien habría intercedido por ellos para que no prestaran el servicio militar obligatorio. En cualquier caso venían de los mismos lugares de los que venían los soldados que llenaban los cuarteles.

En cuanto a la precariedad espiritual y a la rutina, la poca educación formal de los reclutas permitía transmitirles sencillas ideas patrióticas con facilidad, ideas que ya habían sido implantadas en la escuela primaria - en caso de haber asistido a ella - y que ahora justificaban comportamientos cuyo sentido y utilidad no eran evidentes. Según el Agregado norteamericano en Bogotá a los soldados se les inculcaba en primer lugar la lealtad y seguían «ciegamente» las enseñanzas de los oficiales ${ }^{81}$.

No hay duda de que el servicio militar traía frustración a muchos jóvenes pero, al mismo tiempo, la experiencia era demasiado novedosa para descartarla de las razones para no desertar: nuevo vocabulario, nuevas prácticas corporales, nuevos amigos... Por sus características, el paso por el cuartel era una entrada a la edad adulta masculina con armas y pornografía adentro, alcohol y prostitutas al salir de permiso. No debe olvidarse que casi todas las

79 Ministerio de Guerra, 1922: 22.

80 Arguedas, 1983: 195.

81 "Blindly", Agregado militar en Bogotá al Director de Inteligencia Militar en Washington, 14 de septiembre de 1929, NARA, RG 165, 2010, 34-4. 
unidades militares de ambos países estaban destacadas en grandes centros urbanos. En 1924 Luis Londoño, sacerdote jesuita y capellán general del Ejército de Colombia, pedía tomar medidas contra «los peligros de inmoralidad que se encuentran en las ciudades [...] el coartar la licencia para andar por la calles de noche, la prohibición de libros y pinturas indecentes en los cuarteles, etc». Según el cura estos «peligros» eran la causa principal de resistencia al servicio por parte de las familias ${ }^{82}$. La opinión de los soldados era diferente: si bien estas prácticas no eran un motivo para entrar al ejército, sí podían convertirse en un medio de sobrellevar la obligación.

Una de las razones por la que los soldados debían «sobrellevar» más que prestar el servicio militar era la severidad y a veces la iniquidad de oficiales y suboficiales. No hay duda de que la autoridad que otorgaba el grado se prestaba para cometer abusos. Sin embargo, no todos los oficiales eran déspotas: algunos, tal vez muchos, se preocupaban genuinamente por sus hombres, como aquellos que empezaron a construir cuarteles por iniciativa propia en Cali y en Sicuani al empezar los años veinte. Además, entre los soldados y los oficiales superiores se creaban a veces relaciones casi filiales - los últimos podían tener hijos de la edad de los primeros-. Pese a su carácter excepcional las muestras de cariño por parte de sus superiores al soldado Cándido Leguízamo ${ }^{83}$, herido durante el Conflicto de Leticia, muestran que no todo estaba mediado por la jerarquía militar. Aun en las memorias de guerra del sargento Jorge Tobón, el testimonio más agudo escrito en el frente contra las arbitrariedades cometidas por oficiales y también suboficiales, se ve hombres admirables en todos los grados: el teniente Moreno Córdoba, valiente y querido por la tropa; el capitán Laurentino Fernández, quien se hizo respetar y querer en la guarnición de El Encanto al restablecer, por medio de castigos reglamentarios, la disciplina perdida después del cese al fuego; y el coronel Rubén Galvis: «Un hombre macho con el corazón bondadoso de un adolescente. Él grita a ratos, dijo un soldado, pero es bueno como el pan» ${ }^{84}$. El mismo sargento Tobón aparece como un suboficial justo y apreciado por sus hombres.

La vida del soldado era dura aun en tiempos de paz, no cabe duda, pero las adversidades no eran infinitas. Una de las mayores ventajas prácticas de las nuevas leyes sobre servicio militar era dar a los reclutas una fecha fija de salida del cuartel. Algo tan sencillo como una cuenta regresiva, llevada en una pared, un árbol o en las tablas de la cama —en el caso dudoso de que hubie-

\footnotetext{
82 Ministerio de Guerra, 1924: 49.

83 López, 1951: 43-44 y 127-128.

84 Tobón: 31, 42 y 139-140.
} 
ra cama con tablas - , ayudaba a soportar. Las mismas adversidades daban, por contraste, más intensidad a los momentos de alegría, como lo muestra un film del Conflicto de Leticia, en el que aparecen oficiales, suboficiales y soldados boxeando, tocando guitarra, cantando y haciendo clavados en el río Amazonas o Putumayo ${ }^{85}$, situaciones que tenían sus equivalentes en los cuarteles.

\section{CONCLUSIÓN}

La comparación de los casos de Perú y Colombia muestra rasgos comunes a ambos ejércitos: el carácter excepcional del servicio militar, si se tiene en cuenta la diferencia inmensa entre la población masculina en edad de prestarlo y el tamaño ínfimo de los contingentes; la idealización de las virtudes militares de los soldados indígenas o mestizos con predominio étnico americano; y, sobre todo, la precariedad material en que se cumplía la obligación.

Sin embargo, como se dijo en la introducción, la comparación no pudo hacerse en todos y cada uno de los aspectos estudiados debido a la escasez de documentos. Por lo tanto, falta averiguar si algunas características de la experiencia del cuartel en Colombia - mejor cubierta por las fuentes utilizadas - tienen su equivalente en Perú: el desfase entre las aspiraciones de las leyes y las posibilidades reales del Estado para llevar a cabo el reclutamiento en el nivel local 86 ; una tasa de analfabetismo de los conscriptos menor de lo que se había pensado hasta el momento; y la precariedad espiritual en que se prestaba el servicio - que llevaba a matar el tiempo con actividades sin sentido-.

Quedan, desde luego, muchos asuntos por estudiar, entre otros: la negociación cotidiana de la autoridad y la obediencia (órdenes y reclamos, castigos y premios...); la experiencia del cuartel en clave de masculinidad (ritos de paso, educación física, homosexualidad, relaciones con mujeres...); y la geografía detallada del reclutamiento en cada país (niveles regional y local).

A medida que aparezcan fuentes desconocidas hasta el momento estas preguntas podrán encontrar respuesta no sólo en los casos de Perú y Colombia sino también en los de otros ejércitos latinoamericanos.

85 Guerra con el Perú, FPFC, AHCHA, código DVD 6018-6019, hora 1 minuto 37 segundo 32 cuadro 25; hora 1 minuto 42 segundo 18 cuadro 20; hora 1 minuto 44 segundo 3 cuadro 0 .

86 Para los primeros años del siglo XX ver Velásquez, 2013: 343-377. 
FuENTES Y BibLIOGRAFÍA

Arguedas, Alcides, La danza de las sombras (apuntes sobre cosas, gentes y gentezuelas de la América española), Bogotá, Banco de la República, 1983.

Atehortúa, Adolfo, Construcción del ejército nacional en Colombia, 1907-1930. Reforma militar y misiones extranjeras, Medellín, La Carreta, 2009.

Boy, Herbert, Una historia con alas, Madrid, Guadarrama, 1955.

Chanduví, Luis, El APRA por dentro, lo que hice, lo que vi y lo que sé (1931-1957), Lima, Taller gráfico copias e impresiones, 1988.

Díaz, Jenaro, "Soldado Cándido Leguízamo Bonilla: Héroe y mártir 1911-1933. Documental", Revista de las Fuerzas militares, separata (Bogotá, 1972).

Donadio, Alberto, La guerra con el Perú, Bogotá, Planeta, 1995.

López Narváez, Carlos, Putumayo 1933. Diario de guerra, Bogotá, Ediciones Espiral, 1951.

Ministerio de Guerra, Memoria de guerra, Bogotá, Imprenta del Estado Mayor General, 1920, 1922, 1924, 1925, 1927, 1929 у 1931.

Montagne, Ernesto, Memorias del general de brigada Ernesto Montagne Markholz, Lima, Imprenta Colegio militar Leoncio Prado, 1962.

Mora Angueyra, Hernando, "Diario de guerra del cañonera Cartagena", Álvaro Valencia Tovar (ed.), Conflicto Amazónico 1932-1934, Bogotá, Villegas, 1994: 287-303.

National Archives Microfilm Publications, Pamphlet Describing M1271. Registers of Communications Received From Military Attaches and other Intelligence Officers ("Dispatch Lists") 1889-1941, Washington, National Archives Trust Fund Board, National Archives and Records Service, 1984.

Roynette, Odile, "Bons pour le service". L'expérience de la caserne en France à la fin du XIXe siècle, París, Belin, 2000.

Rueda Vargas, Tomás, El ejército nacional, Bogotá, Imprenta y litografía de las Fuerzas Militares, 1969.

Rueda Vargas, Tomás, La sabana y otros escritos del campo, de la ciudad y de sí mismo, Bogotá, Instituto Caro y Cuervo, 1977.

Tobón Restrepo, Jorge, Sur, memorias de un suboficial, Bogotá, Tipografía París, s. d.

Uribe, Alejandro, Conferencia dictada en el salón de conferencias de la Universidad Javeriana, Bogotá, Talleres del Estado Mayor General, 1933.

Velásquez, David, La reforma militar y el gobierno de Nicolás de Piérola. El ejército moderno y la construcción del Estado Peruano, tesis de maestría en historia, Lima, Universidad Nacional Mayor de San Marcos, 2013. 
Fecha de recepción: 17 de junio de 2015.

Fecha de aceptación: 24 de julio de 2015.

\section{Recruitment, soldiers and the experience of army life: compulsory military service in Peru and Colombia (1919-1933)}

The article studies different aspects of mandatory military service in Peru and Colombia from 1919 to 1933 including recruitment; the social, "racial", and geographical origins of soldiers; and army life in both countries. Documents from military archives in the U.S. and France, as well as writings from Peruvian and Colombian commissioned and non-commissioned officers were the main sources used. The method is comparative and it shows clear features in common, including the scarcity of resources that affected all aspects of service.

KeY words: Colombia; Leticia Conflict; Peru; recruitment; military service; soldiers. 